Article

\title{
Novel High-Efficiency Three-Port Bidirectional Step-Up/Step-Down DC-DC Converter for Photovoltaic Systems
}

\author{
Yu-En Wu*D and Shiu-Liang Hsiao
}

Department of Electronic Engineering, National Kaohsiung University of Science and Technology, Kaohsiung 824, Taiwan; u0552822@nkfust.edu.tw

* Correspondence: yew@nkust.edu.tw; Tel.: +886-7-6011000 (ext. 32511)

check for updates

Citation: Wu, Y.-E.; Hsiao, S.-L. Novel High-Efficiency Three-Port Bidirectional Step-Up/Step-Down DC-DC Converter for Photovoltaic Systems. Sustainability 2021, 13, 7913. https://doi.org/10.3390/su13147913

Academic Editor: Gerardo

Maria Mauro

Received: 13 June 2021

Accepted: 13 July 2021

Published: 15 July 2021

Publisher's Note: MDPI stays neutral with regard to jurisdictional claims in published maps and institutional affiliations.

Copyright: (c) 2021 by the authors. Licensee MDPI, Basel, Switzerland. This article is an open access article distributed under the terms and conditions of the Creative Commons Attribution (CC BY) license (https:/ / creativecommons.org/licenses/by/ $4.0 /)$.

\begin{abstract}
This paper presents a novel high-efficiency three-port bidirectional DC-DC converter for photovoltaic (PV) systems. A PV system's output is stepped up to supply a DC bus or DC load while charging the battery. When the PV output is insufficient, the battery voltage is stepped up to the DC bus; when the DC bus has excess energy, it is stepped down to charge the battery. Thus, a high-efficiency three-port bidirectional step-up/step-down converter is achieved. A common-core coupled inductor was designed and adopted in the proposed converter. Power switches and diodes in the circuit are shared to achieve bidirectional operation. In step-up mode, the clamp capacitor is used to reduce the voltage spike on the main switches. Moreover, the voltage-doubling capacitor recovers energy from the secondary-side leakage inductance. Furthermore, the input capacitors recover the primary-side leakage inductance energy in step-down mode. Thus, the converter can improve its conversion efficiency. Finally, this paper details the implementation of a $500 \mathrm{~W}$ three-port bidirectional converter to verify the feasibility and the practicability of the proposed topology. According to the measurement results, the highest efficiency levels of the PV and the battery in step-up mode were $94.3 \%$ and $94.1 \%$, respectively; the highest efficiency in step-down mode was $95.2 \%$.
\end{abstract}

Keywords: three-port bidirectional converter; coupled inductor; photovoltaic system

\section{Introduction}

In recent years, greenhouse gas emissions increased with advances in technology, leading to global warming and climate change. The energy technology industry continues to be heavily dependent on fossil fuels and is unable to handle this stringent environment. Therefore, the use of green energy became the core of major economic strategies and is a key focus in world politics, especially because reducing greenhouse gas emissions and conserving energy are the main global concerns at present [1].

Green energy is extremely affected by environmental factors; for example, solar power generation systems are often affected by duration, intensity, and angle of sunshine, which affect the quantity and the stability of power supply. Thus, green energy is inconvenient and unstable to use. Therefore, a converter is needed to convert the voltage before it can be effectively used [2-8]. Traditional isolated converters are more widely used, such as flyback converter, forward converter, and push-pull converter, which improve safety, provide galvanic isolation, improve anti-noise ability, etc., and can be used in more windings added to the transformer to output a variety of voltage values [9-11]. In order to reduce cost and volume, in recent years, many bidirectional converters with step-up/step-down function were presented [12-16]. A traditional non-isolated bidirectional converter such as a buck/boost bidirectional converter is also widely used [12]. Such a converter has the advantages of relatively low component count and cost but the disadvantage of a poor voltage conversion ratio. In high-efficiency bidirectional conversion executed using a coupled inductor converter [13], a clamp capacitor can be applied to reduce the voltage 
stress and recover stray energy; however, such converters do not have an electrical isolation function, making circuit and switch control signals susceptible to interference. In addition, many isolated bidirectional converters were proposed recently [14,16]. For example, [14] proposed a high-efficiency single-input multiple-output bidirectional isolated converter in which the leakage inductance energy of the coupled inductor is recovered through the clamp capacitor to the power supply terminal, and zero-voltage switching (ZVS) is implemented in the converter switch to reduce the switching loss; however, the auxiliary power supply terminal cannot be stepped down/stepped up to other power supply terminals in this topology.

Three-port bidirectional converters are appealing alternatives. Figure 1 illustrates the general application diagram of a three-port bidirectional converter. Because photovoltaic (PV) systems use PV energy for energy production, lack of sunshine would lead to inadequate energy. Therefore, an energy storage system must be developed to store more energy during the day or to satisfy excess energy demands through a battery. When a PV system generates insufficient or no energy owing to environmental factors or it being night, energy is supplied by a battery, thereby considerably improving the stability of the energy system [17-19].

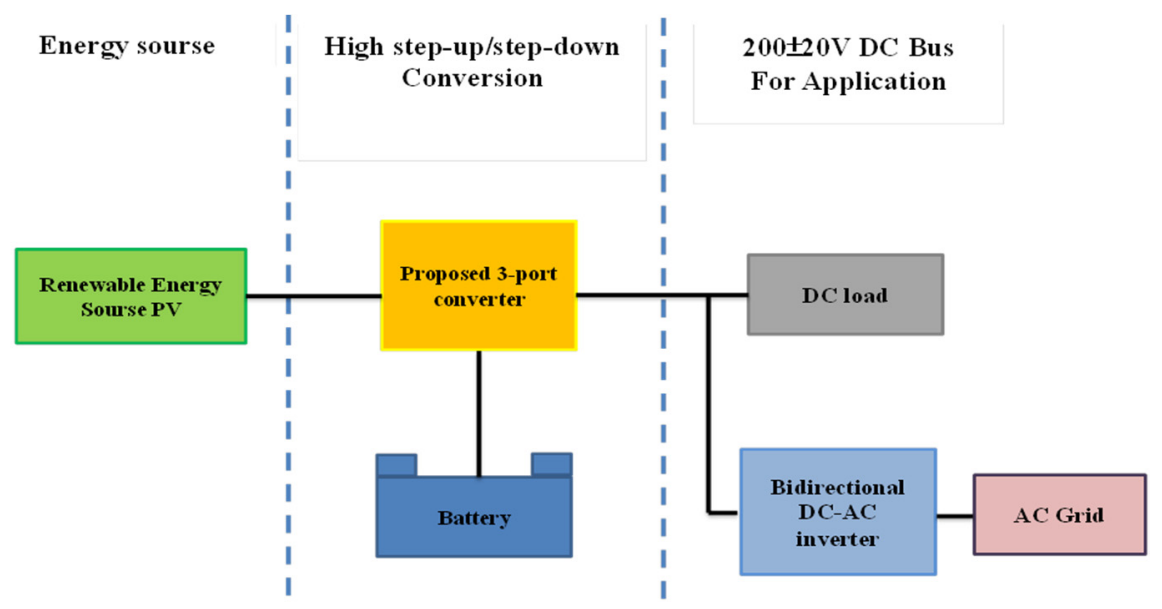

Figure 1. Application diagram of three-port bidirectional converter.

This study proposes a high-efficiency three-port bidirectional DC-DC converter for PV systems. In the proposed converter, the PV system output is stepped up to the DC bus, and the battery charges simultaneously. When solar energy changes rapidly due to environmental factors, the battery ports energy to the DC bus to stabilize the overall system. When solar energy is unavailable, the DC bus can release energy to the battery, and the proposed converter is used for charged energy storage. The proposed PV system's output and battery port are stepped up and supply energy to the DC bus load. At other times, the PV system and the battery port are each supplied with DC load (the DC load here refers to all DC-powered equipment). When commercial power stops, the battery port is used as the main energy supply. When power demand is lower (e.g., at night), the DC bus charges the battery voltage. The three-port bidirectional converter proposed in this paper has the following advantages: (1) high voltage gain, (2) high efficiency, (3) low components voltage stress, and (4) three-port power transmission function.

\section{Circuit Architecture and Operation Principle}

The circuit architecture of the proposed converter (Figure 2) involves three operating modes. At stage 1, when PV output is sufficient, energy is stepped up to the DC bus and is used to charge the battery. At stage 2, when no PV energy is available, battery power is separately stepped up to the DC bus. At stage 3, when no PV energy is available and the battery power is insufficient, the battery is charged by the DC bus. 


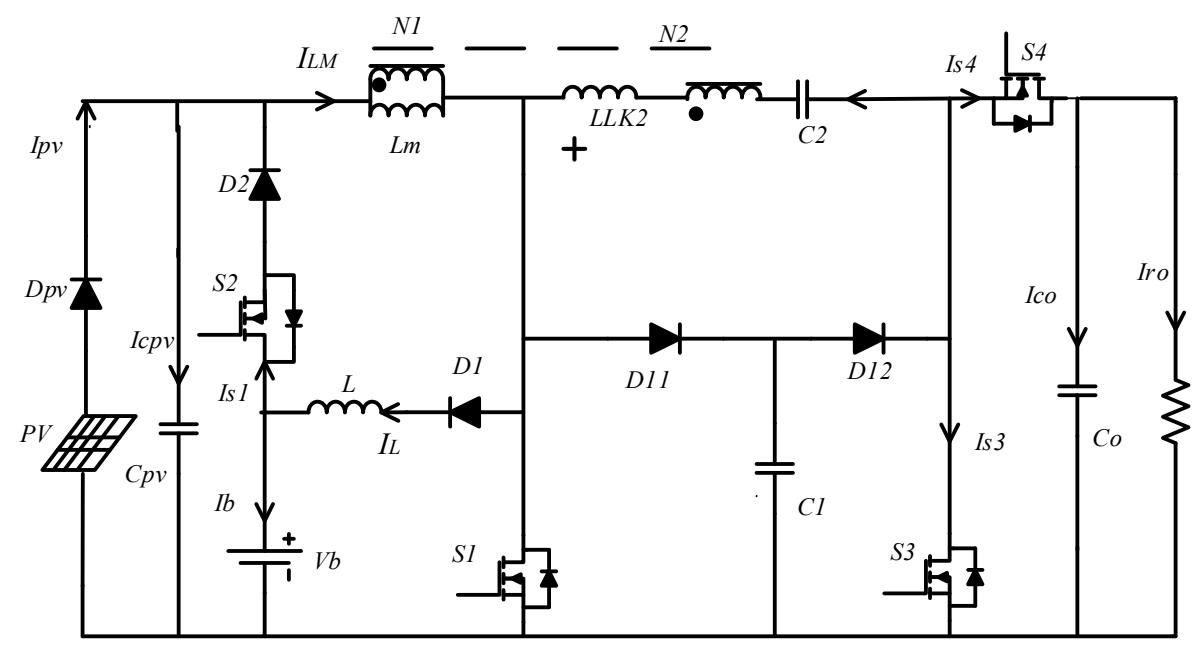

Figure 2. Proposed three-port bidirectional DC-DC converter.

To simplify the circuit study, the following assumptions are made:

- $\quad$ all of the circuit components are ideal;

- $\quad$ the sizes of capacitors are sufficiently large to be considered constant voltage sources;

- the sizes of inductances are sufficiently large to be considered constant current sources.

A. Stage 1: PV system output is stepped up to DC bus to charge battery. Figure 3 shows the key waveforms of each operating mode in stage 1.

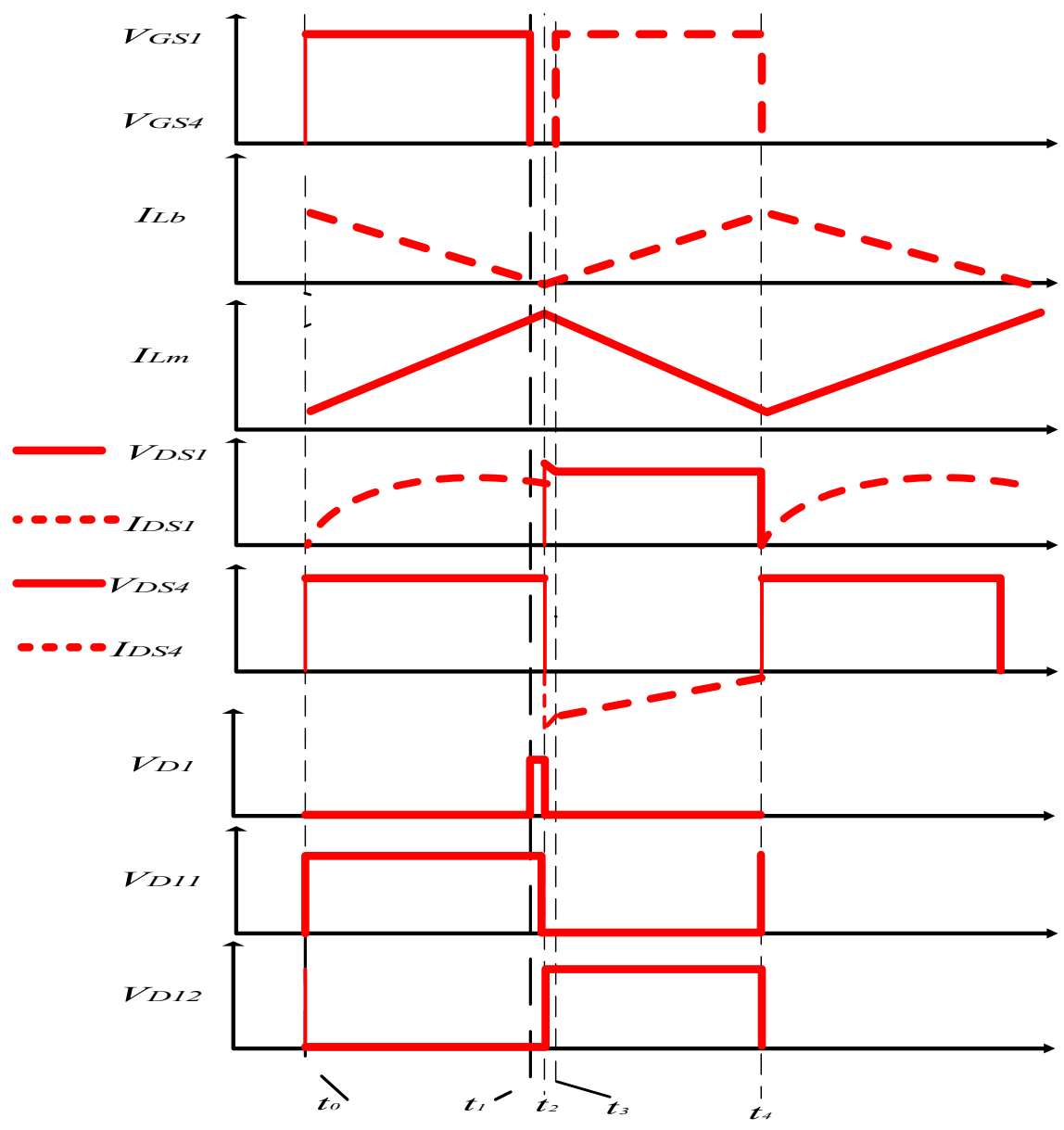

Figure 3. Key waveforms of each operating mode in stage 1. 


\section{Mode I $\left(t_{0}-t_{1}\right)$}

At $t=t_{0}$ (where $t$ is the operating time), the switch $S 1$ and the switch $S 4$ body diodes are turned on. The diodes $D_{1}$ and $D_{12}$ are turned on, and the diode $D_{11}$ is turned off. The equivalent circuit is shown in Figure $4 \mathrm{a}$. The input voltage $V_{p v}$ provides energy to the magnetizing inductance $L_{m}$ of the primary side core, and the energy is forwarded to the secondary side. The inductor $L$ energy is released to the battery port until the inductor $i_{L}$ current decreases to zero, and the output is provided by $C_{1}$ and $C_{2}$.

2. Mode II $\left(t_{1}-t_{2}\right)$

At $t=t_{1}$, the switch S1 is turned on, the diode $D_{12}$ is turned on, and the diodes $D_{1}$ and $D_{11}$ are turned off. The equivalent circuit is illustrated in Figure $4 \mathrm{~b}$. The input voltage $V_{p v}$ provides energy to the magnetizing inductance $L_{m}$ of the primary-side core, and the energy is forwarded to the secondary side. The capacitor $C_{1}$ is charged by the capacitor $C_{2}$ stray energy, and the inductor $L$ releases energy to the battery port. The output energy is provided by $C_{0}$.

3. Mode III $\left(t_{2}-t_{3}\right)$

At $t=t_{2}$, the switch $S 1$ is turned off, the diodes $D_{1}$ and $D_{11}$ are turned on, and the diode $D_{12}$ is turned off. The equivalent circuit is presented in Figure 4c. The leakage inductor $L_{l k 2}$ stores freewheeling-current or energy in the inductor $L$. The capacitor $C_{1}$ clamps the surge voltage of the switch S1.

\section{Mode IV $\left(t_{3}-t_{4}\right)$}

At $t=t_{3}$, the switch S4 is turned off, and the diodes $D_{1}$ and $D_{11}$ are turned on, and the diode $D_{12}$ is turned off. The equivalent circuit is shown in Figure $4 \mathrm{~d}$. The magnetizing inductance $L_{m}$ releases energy to the output to provide the load and charge the capacitor $C_{0}$. The magnetizing inductance $L_{m}$ part of the energy and the inductor $L$ are released to the battery port for charging.

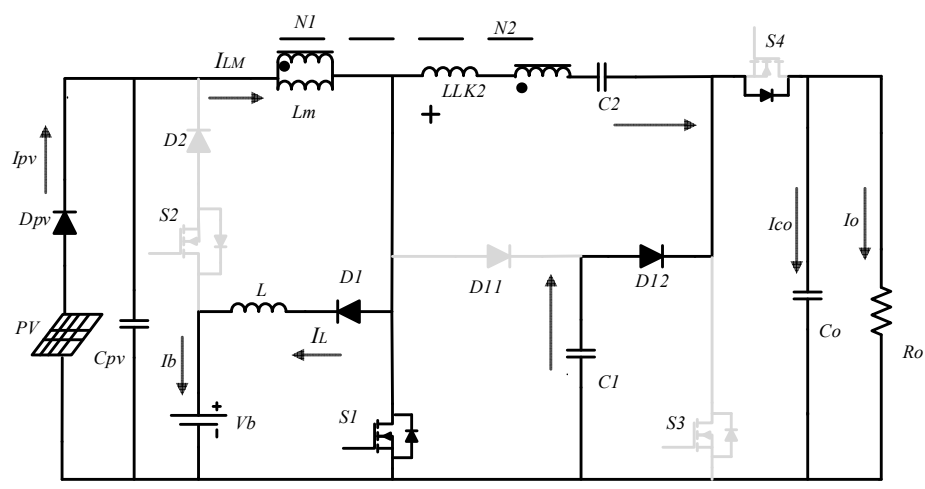

(a) Mode I

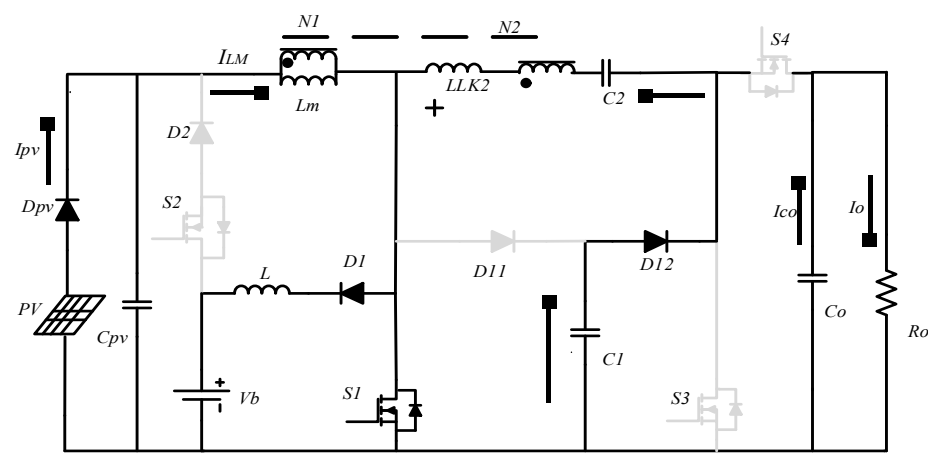

(b) Mode II

Figure 4. Cont. 


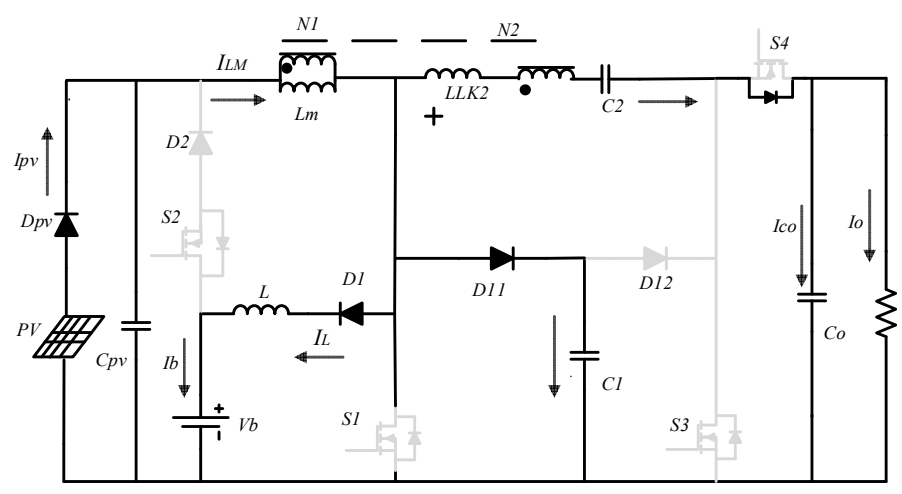

(c) Mode III

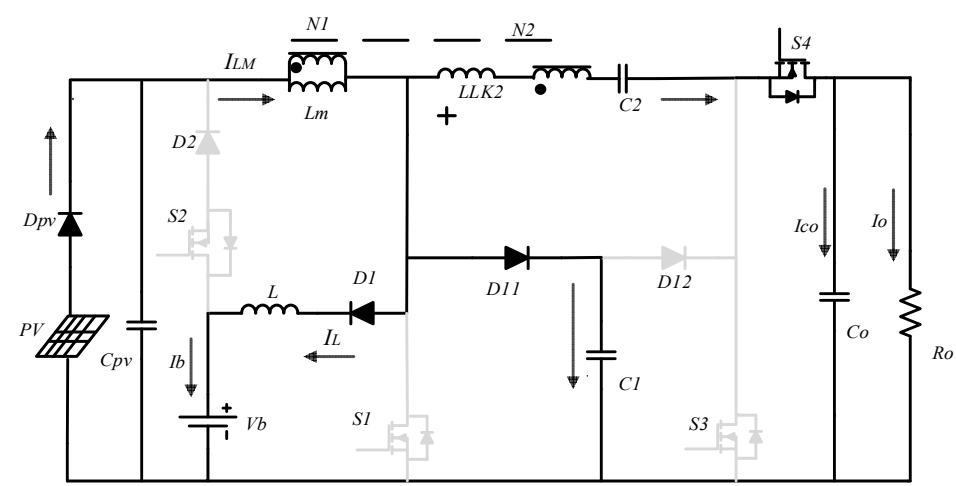

(d) Mode IV

Figure 4. Equivalent circuit of the proposed converter operated in stage 1 (a) mode I, (b) mode II, (c) mode III, and (d) mode IV.

B. Stage 2: Battery is stepped up to DC bus

Figure 5 shows the key waveforms of each operating mode in stage 2.

1. Mode I $\left(t_{0}-t_{1}\right)$

At $\mathrm{t}=\mathrm{t}_{0}$, the switches $\mathrm{S} 1, \mathrm{~S} 2$, and $\mathrm{S} 4$ body diodes are turned on. The diodes $D_{1}$ and $D_{11}$ are turned on, and the diode $D_{12}$ is turned off. The equivalent circuit is illustrated in Figure 6a. The battery port $V_{b}$ provides energy to the magnetizing inductance $L_{m}$ and the capacitor $C_{p v}$. The output load energy is supplied by the capacitors $C_{1}$ and $C_{2}$.

2. Mode II $\left(t_{1}-t_{2}\right)$

At $t=t_{1}$, the switches S1 and S2 are turned on, and the diodes $D_{1}$ and $D_{11}$ are turned off; the diode $D_{12}$ is turned on. The equivalent circuit is displayed in Figure $6 \mathrm{~b}$. The battery port $V_{b}$ continues to provide energy for the magnetizing inductance $L_{m}$. The output capacitance $C_{o}$ releases energy to the load $R_{o}$.

3. Mode III $\left(t_{2}-t_{3}\right)$

At $t=t_{2}$, the switches S1 and S2 are turned off, and the diodes $D_{1}$ and $D_{11}$ are turned on; the diodes $D_{2}$ and $D_{12}$ are turned off. The equivalent circuit is shown in Figure 6c. The leakage inductance $L_{l k 2}$ releases freewheeling current or energy to the inductor $L$. The capacitor $C_{1}$ clamps the surge voltage of the switch $\mathrm{S1}$, and the output energy is provided by the capacitor $C_{2}$.

4. Mode IV $\left(\mathrm{t}_{3}-\mathrm{t}_{4}\right)$

At $t=t_{3}$, the switch S4 is turned on, the diodes $D_{1}$ and $D_{11}$ are turned on, and the diodes $D_{2}$ and $D_{12}$ are turned off. The equivalent circuit is presented in Figure $6 \mathrm{~d}$. The magnetizing inductance $L_{m}$ releases energy to provide the load and recovers energy through the capacitor $C_{0}$. The magnetizing inductance $L_{m}$ and the inductance $L$ release energy to charge the battery. 


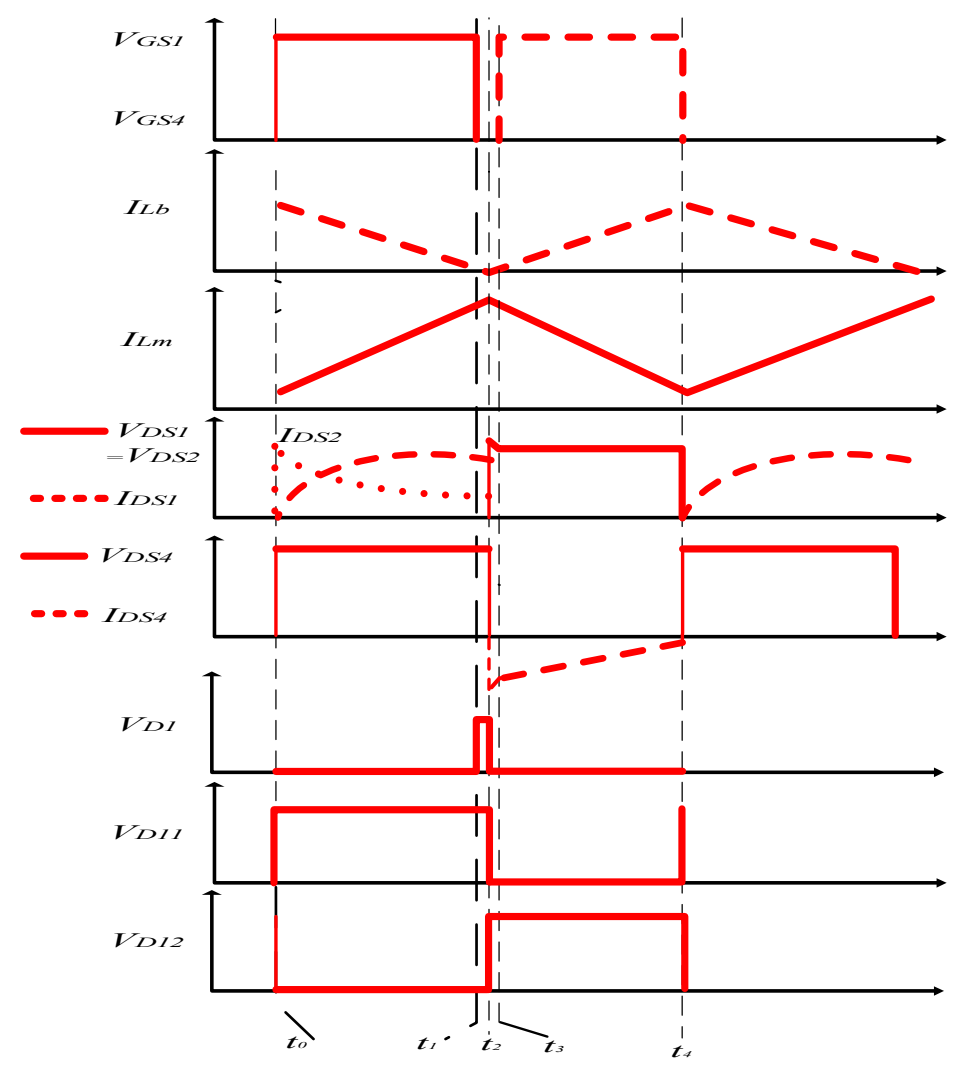

Figure 5. Key waveforms of each operating mode in stage 2.

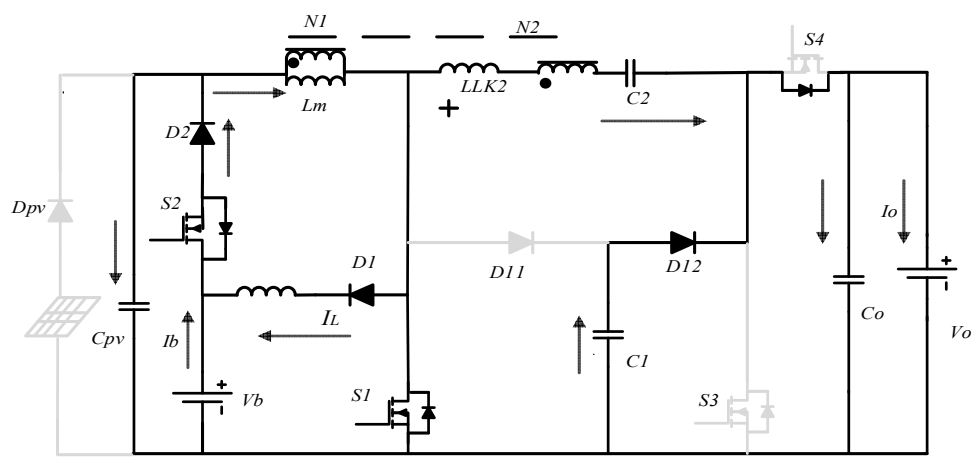

(a) Mode I

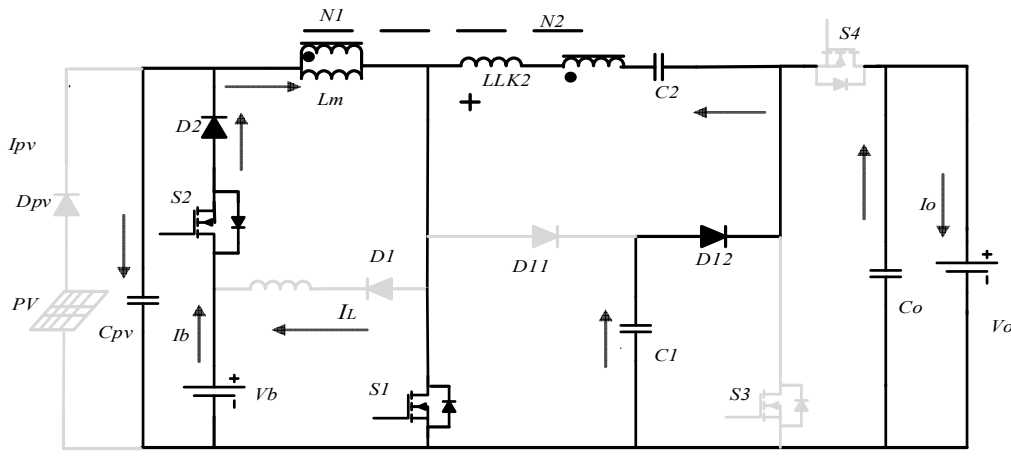

(b) Mode II

Figure 6. Cont. 


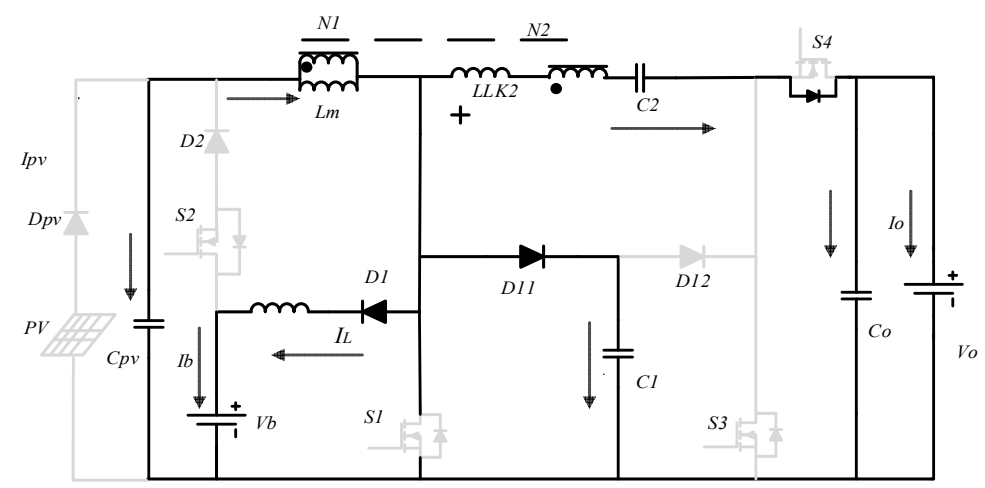

(c) Mode III

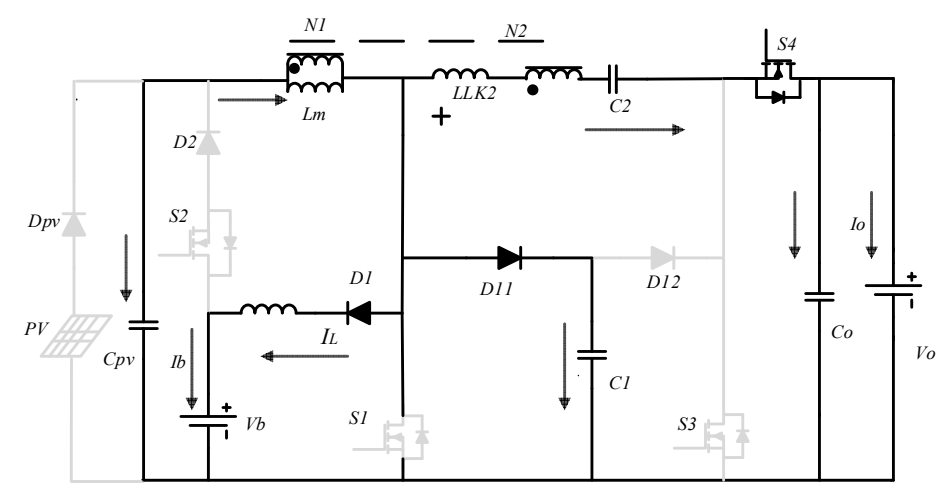

(d) Mode IV

Figure 6. Equivalent circuit of each operating mode in stage 2 (a) mode I, (b) mode II, (c) mode III, and (d) mode IV.

C. Stage 3: DC bus is stepped down to charge the battery

Figure 7 illustrates the key waveforms of each operating mode in stage 3.

1. Mode I $\left(t_{0}-t_{1}\right)$

At $t=t_{0}$, the switch $S 4$ and the switch $S 1$ body diode are turned on, and the diode $D_{12}$ is turned on; the diode $D_{11}$ is turned off. The equivalent circuit is illustrated in Figure 8a. The DC bus provides energy to the magnetizing inductance $L_{m}$. The transformer leakage inductance $L_{l K 1}$ energy is recovered by the capacitor $C_{p v}$. At this time, the inductor $L$ can release energy to the battery.

2. Mode II $\left(t_{1}-t_{2}\right)$

At $t=t_{1}$, the switch S4 and the switch S1 body diode are turned on, and the diode $D_{12}$ is also turned on; the diode $D_{11}$ is turned off. The equivalent circuit is shown in Figure $8 \mathrm{~b}$. The leakage inductance $L_{l K 1}$ energy is recovered by the capacitor $C_{p v}$, and the leakage inductance $L_{l k 2}$ continues to charge the inductor $L$.

3. Mode III $\left(t_{2}-t_{3}\right)$

At $t=t_{2}$, the switch S3 and the diode $D_{11}$ are turned on, and the equivalent circuit is illustrated in Figure 8c. The magnetizing inductance $L_{m}$ discharges energy to the inductor $L$ and charges the battery.

4. Mode IV $\left(\mathrm{t}_{3}-\mathrm{t}_{4}\right)$

At $t=t_{3}$, the switch S3 and the diode $D_{12}$ are turned on, and the equivalent circuit is displayed in Figure 8c. The magnetizing inductance $L_{m}$ discharges energy to the inductor $L$ and charges the battery. 


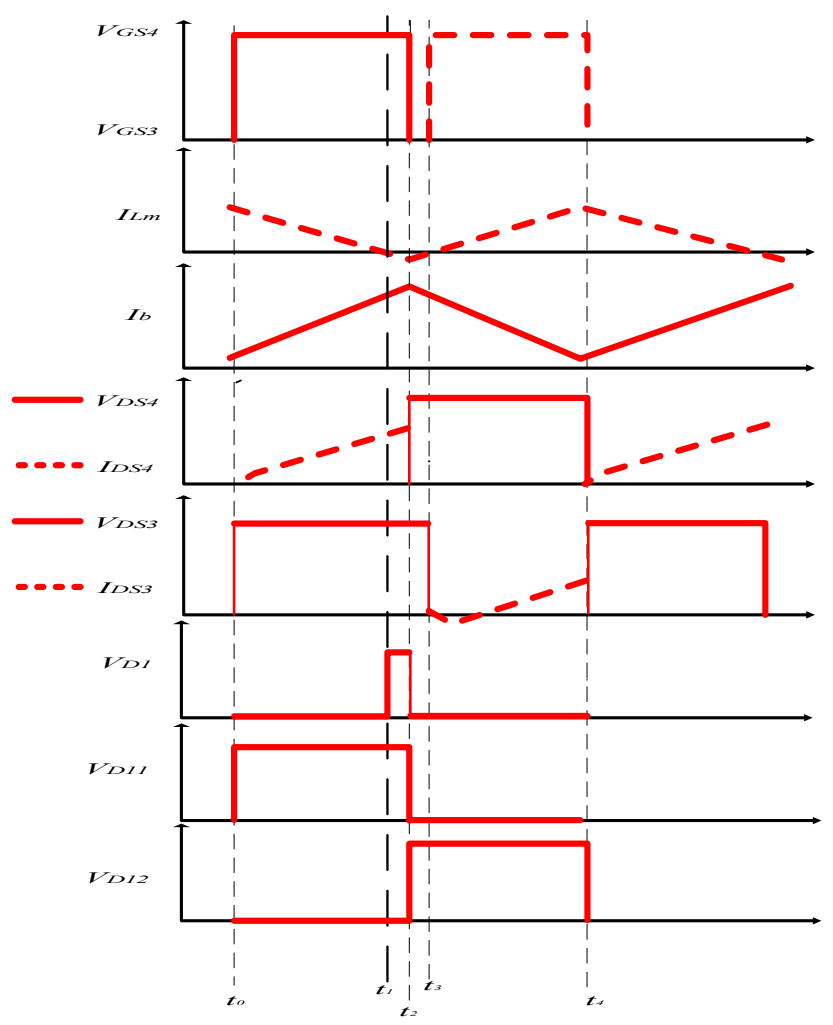

Figure 7. Key waveforms of each operating mode in stage 3.

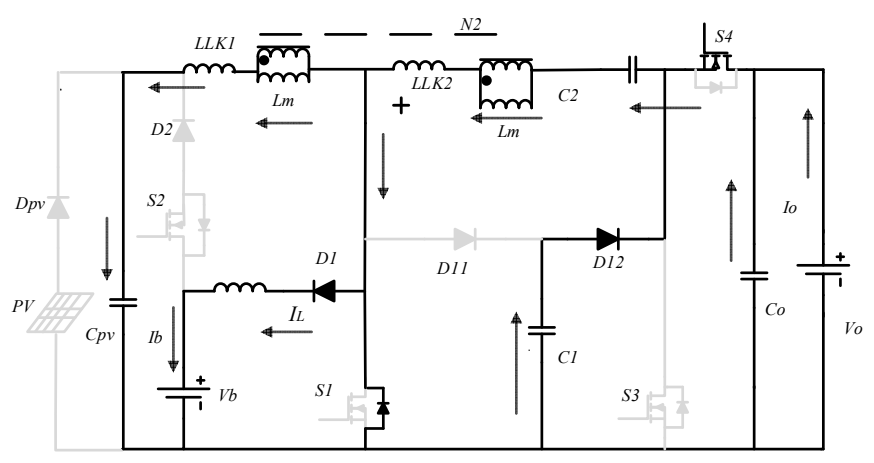

(a) Mode I

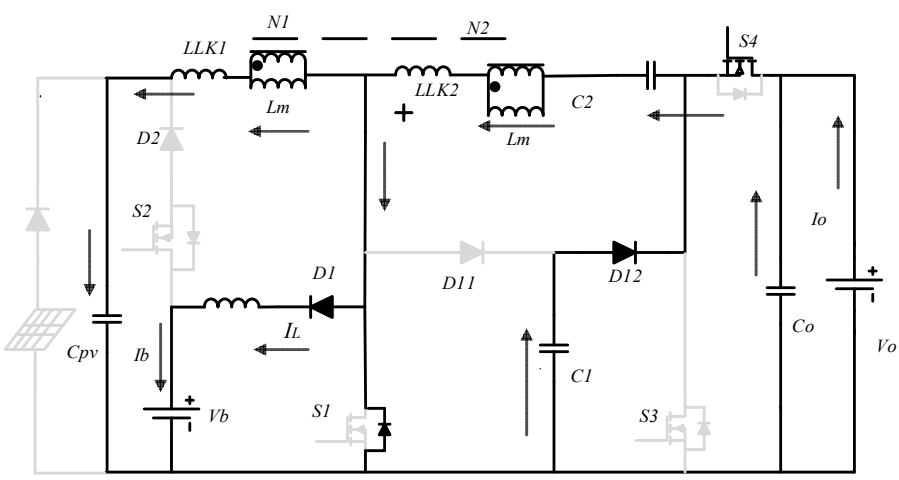

(b) Mode II

Figure 8. Cont. 


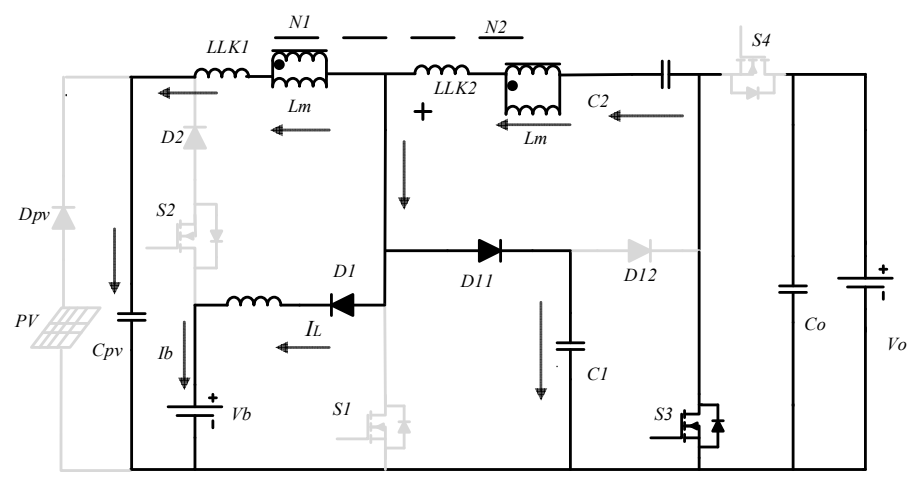

(c) Mode III

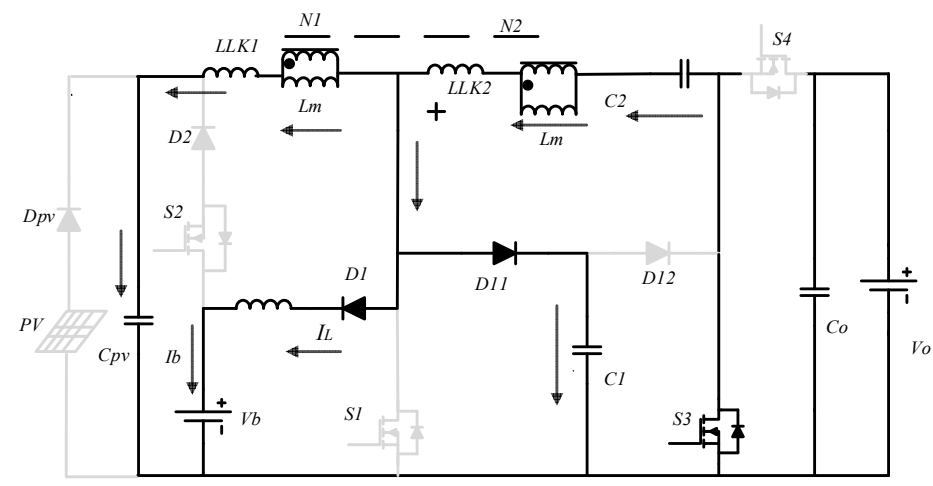

(d) Mode IV

Figure 8. Equivalent circuit of each operating mode in stage 3 (a) mode I, (b) mode II, (c) mode III, and (d) mode IV.

\section{Steady State Analysis}

To simplify the circuit analysis, in addition to the assumptions in the second section, the following assumptions are also added:

The magnetizing inductance of each winding is much larger than its leakage inductance.

A. Voltage gain ratio

In stage 1, PV energy is stepped up to the DC bus to charge the battery, and the switches S1 and S4 are complementarily turned on. The following equations can be derived on the basis of Kirchhoff's voltage law.

When the switch S1 is turned on:

$$
V_{P V}=V_{L m}
$$

the voltage on the capacitor $\mathrm{C} 1$ is:

$$
V_{C 1}=V_{P V} \frac{1}{1-D}
$$

The voltage on the capacitor $C 2$ is:

$$
V_{C 2}=N V_{L m}+V_{C 1}=V_{L m} \frac{1+N-N D}{1-D}
$$

Equations (1) and (3) can be substituted into $V_{o}$ :

$$
V_{o}=\left(1+\frac{D}{1-D}+\frac{N D}{1-D}\right) V_{P V}+V_{C 2}=\frac{2+N}{1-D} V_{P V}
$$


Organizing Equation (4) can yield the voltage gain as follows:

$$
\frac{V_{o}}{V_{P V}}=\frac{2+N}{1-D}
$$

At stage 3, the DC bus is stepped down to charge the battery; thus, the following equations can be obtained on the basis of Kirchhoff's voltage law:

$$
V_{b}=V_{L m}=V_{o}-V_{C 2}-V_{C 1}
$$

When the switch S4 is turned on:

$$
V_{b}=\frac{1}{N} V_{L m}=V_{N 1}
$$

When the switches S3 and S4 are complementarily turned on:

$$
V_{L}=V_{o}-V_{C 2}-V_{C 1}=L \frac{d i_{L}}{d t}
$$

The voltage of the inductor $L$ is:

$$
V_{L}=V_{P V}-V_{N 1}-V_{b}=L \frac{d i_{L}}{d t}
$$

According to the volt-second balance principle, the amount of change in the charging current of the inductor $L$ can be equal:

$$
\Delta i_{L}^{+}=\Delta i_{L}^{-}
$$

Therefore:

$$
\frac{V_{b}}{V_{o}}=\frac{D}{2+N}
$$

B. Voltage stress of components

The voltage stress of the component can be analyzed by turning the switch on or off. When the switch $\mathrm{S} 1$ is turned on, the voltage stress can be ascertained as in Figure 4a in mode I of stage 1.

$$
V_{P V}=V_{L m}
$$

When the switch S1 is turned off, the voltage stress can be ascertained as in Figure 4c in mode III of stage 1.

$$
V_{S 1}=V_{P V}-V_{L m}
$$

According to the volt-second balance principle:

$$
V_{L m} D T=-V_{L m}(1-D) T
$$

Arranging Equations (13) and (14) can yield the voltage stress of the switch S1 as follows:

$$
V_{S 1}=\frac{V_{P V}}{1-D}
$$

The voltage stress of the capacitor $C 1$ is:

$$
V_{C 1}=V_{S 1}
$$

When the diode $D 2$ is assumed to be an ideal component and the switch S2 is turned off, the voltage stress of the switch S2 can be known as per Figure $6 \mathrm{c}$ in mode III of stage 2:

$$
V_{S 2}=V_{b}-V_{P V}
$$


When the switch S4 is turned off, the voltage stress of the switch S4 can be calculated as per Figure $8 \mathrm{c}$ in mode III of stage 3:

$$
V_{S 4}=V_{o}
$$

In stage 2, the voltage stress of the diode $D 2$ is the same as that of the switch S2:

$$
V_{D 2}=V_{b}-V_{P V}
$$

When the switch $\mathrm{S} 1$ is turned on, the voltage stress of the diode D2 can be determined as Figure $4 \mathrm{~b}$ in mode II of stage 1 :

$$
V_{D 2}=V_{b}
$$

The voltage stress of the output capacitor $C_{0}$ is:

$$
V_{C_{o}}=V_{o}
$$

The voltage stress of the capacitor $C 2$ is:

$$
V_{C 2}=V_{C 1}+V_{L m}
$$

In stage 3, the voltage stress of the switch S3 is the same as that of the switch S4:

$$
V_{S 3}=V_{S 4}
$$

\section{Experimental Results}

This section presents experiments conducted to verify the feasibility and the stability of the converter proposed in this paper. First, the electrical specifications of the main circuit and the selected components are introduced. Voltage and current waveforms of the components were separately measured to verify the integrity of the entire research results. The electrical specifications and the component parameters of the circuit are listed in Tables 1 and 2.

Table 1. Electrical specifications of the proposed converter.

\begin{tabular}{cc}
\hline Parameter & Specification \\
\hline Input DC Voltage $V_{P V}$ & $24 \sim 26 \mathrm{~V}$ \\
\hline Battery Voltage $V_{b}$ & $24 \mathrm{~V}$ \\
\hline Output DC Voltage $V_{o}$ & $200 \mathrm{~V}$ \\
\hline Maximum output power $P_{o}$ & $500 \mathrm{~W}$ \\
\hline Switching frequency & $50 \mathrm{kHz}$ \\
\hline Turns ratio & $\mathrm{N}_{1}: \mathrm{N}_{2}=1: 1$ \\
\hline
\end{tabular}

Table 2. Component parameters of the proposed converter.

\begin{tabular}{cc}
\hline Component Parameter & Specification \\
\hline$S_{1} \backslash S_{2}$ (Power MOSFET) & IRFP4321 (150 V/78 A) \\
\hline$S_{3} \backslash S_{4}$ (Power MOSFET) & IRFP4868 (300 V/70 A) \\
\hline$C_{P V}$ (Electrolytic Capacitor) & $100 \mu \mathrm{F} / 100 \mathrm{~V}$ \\
\hline$C_{1}$ (MPP Film Capacitor) & $10 \mu \mathrm{F} / 200 \mathrm{~V}$ \\
\hline$C_{2}$ (Electrolytic Capacitor) & $4.7 \mu \mathrm{F} / 300 \mathrm{~V}$ \\
\hline$C_{o}$ (Electrolytic Capacitor) & $470 \mu \mathrm{F} / 400 \mathrm{~V}$ \\
\hline
\end{tabular}


Table 2. Cont.

\begin{tabular}{cc}
\hline Component Parameter & Specification \\
\hline$L$ (MPP Ring core $)$ & $25 \mu \mathrm{H}$ \\
\hline Diode $D_{1} \backslash D_{2}$ & SBR30A45CT $(45 \mathrm{~V} / 30 \mathrm{~A})$ \\
\hline Diode $D_{11} \backslash D_{12}$ & MBR40200 $(200 \mathrm{~V} / 40 \mathrm{~A})$ \\
\hline
\end{tabular}

A. Stage 1: PV system output is stepped up to DC bus to charge the battery

Figure $9 \mathrm{a}-\mathrm{d}$ illustrate the measurement results obtained when the converter operated under its full load of $500 \mathrm{~W}$ in stage 1. Figure 9a illustrates $V_{d s}$ and $V_{g s}$ waveforms of the switches S1 and S4, respectively. The voltage stress values of S1 and S4 were 70 and $170 \mathrm{~V}$, respectively. The current waveforms of the switches S1 and S4 are displayed in Figure 9b,c. Figure $9 \mathrm{~d}$ presents the primary-side and the secondary-side current waveforms of the inductor $L$.

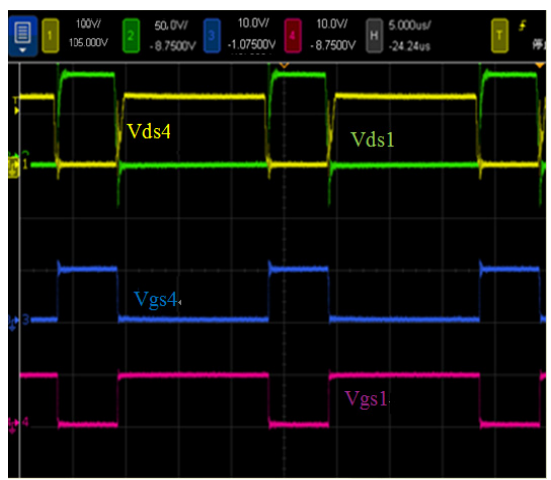

(a) $\left(V_{d s 4}(\mathrm{ch} 1): 100 \mathrm{~V} / \mathrm{div}, V_{d s 1}\right.$ (ch2):50V/div, $V_{s s 1}(\mathrm{ch} 3): 10 \mathrm{~V} / \mathrm{div}, V_{8 s 1}(\mathrm{ch} 4): 10 \mathrm{~V} / \mathrm{div}$

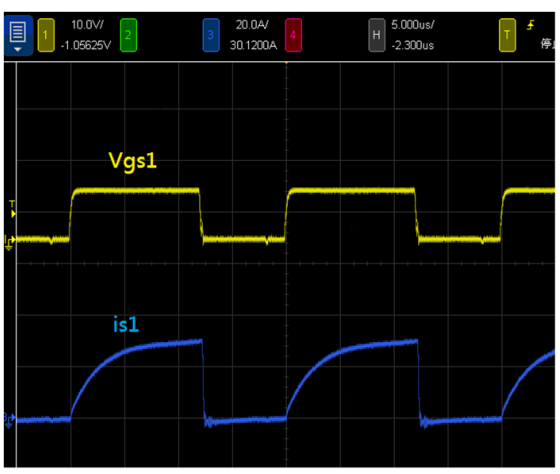

(b) $\left(V_{g^{s 1}}\right.$ (ch1):10V/div, $\left.I_{s 1}(\mathrm{ch} 3): 20 \mathrm{~A} / \mathrm{div}\right)$

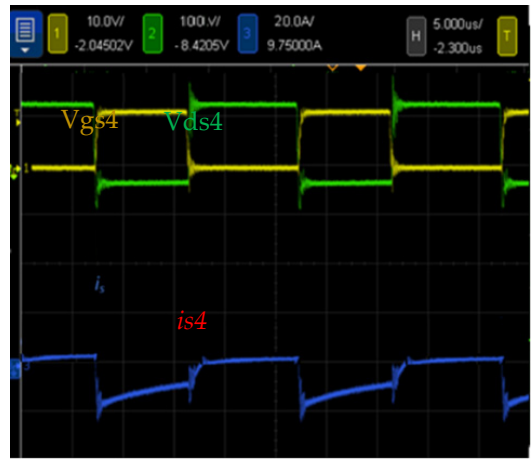

(c) $\left(V_{s^{s}}(\mathrm{ch} 1): 10 \mathrm{~V} / \mathrm{div}, V_{d s 4}(\mathrm{ch} 2): 100 \mathrm{~V} / \mathrm{div}, i_{s 4}(\mathrm{ch} 3): 20 \mathrm{~A} / \mathrm{div}\right)$

Figure 9. Cont. 


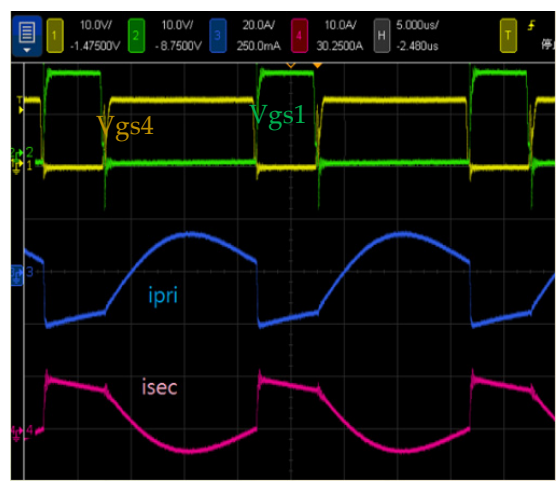

(d) $\left(V_{g^{s 1}}(\mathrm{ch} 1): 10 \mathrm{~V} / \mathrm{div}, V_{g^{s} 4}(\mathrm{ch} 2): 10 \mathrm{~V} / \mathrm{div}, i_{p}(\mathrm{ch} 3): 20 \mathrm{~A} / \mathrm{div}, i_{s e c}(\mathrm{ch} 4): 10 \mathrm{~A} / \mathrm{div}\right)$

Figure 9. Measured waveforms of the proposed converter operating under full load (500 W) in stage 1: (a) $V_{d s}$ and $V_{g s}$ waveforms of the switches S1 and S4, (b) current waveforms of switch S1, (c) current waveforms of switch S4, and (d) primary-side and the secondary-side current waveforms of the inductor $L$.

\section{B. Stage 2: Battery is stepped up to DC bus}

Figure $10 \mathrm{a}-\mathrm{d}$ display the measurement results obtained when the converter operated under its full load of $500 \mathrm{~W}$ in stage 2. Figure 10a shows $V_{d s}$ and $V_{g s}$ waveforms of the switches S1 and S4, respectively. The voltage stress values of S1 and S4 were 70 and $170 \mathrm{~V}$, respectively. The current waveforms of the switches S1 and S4 are presented in Figure 10b,c. Figure 10d illustrates the primary-side and the secondary-side current waveforms of the inductor $L$.

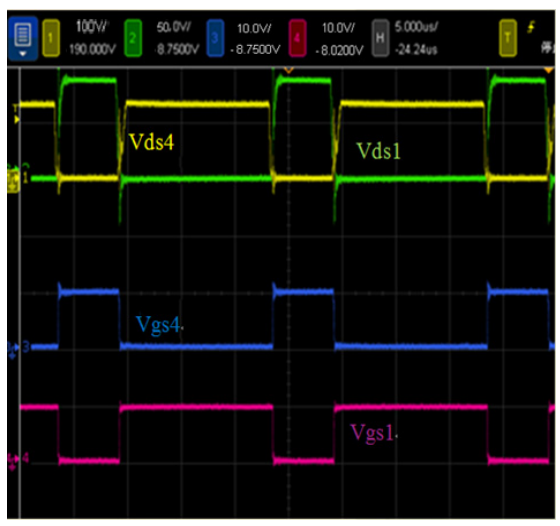

(a) (Vds4(ch1):100V/div, Vds1 (ch2):50V/div, $V_{s s 1}(\mathrm{ch} 3): 10 \mathrm{~V} / \mathrm{div}, V_{s^{s 1}}$ (ch4):10V/div

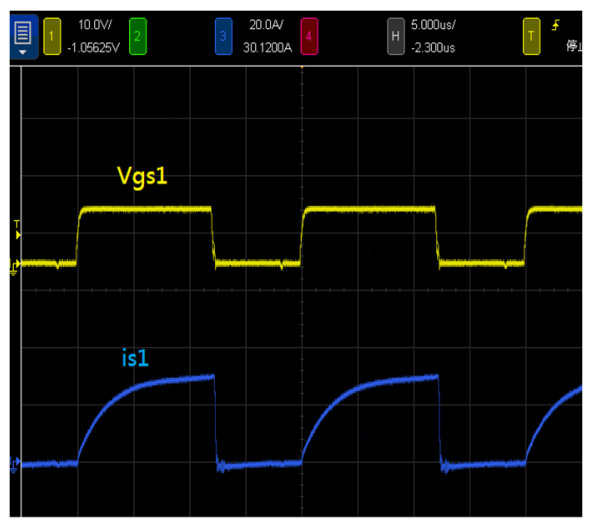

(b) $\left(V_{g^{s 1}}(\mathrm{ch} 1): 10 \mathrm{~V} / \mathrm{div}, I_{s 1}(\mathrm{ch} 3): 20 \mathrm{~A} / \mathrm{div}\right)$

Figure 10. Cont. 


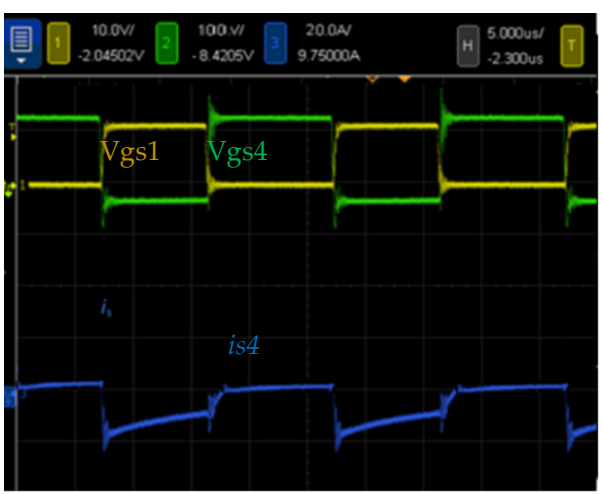

(c) $\left(V_{g s 4}(\mathrm{ch} 1): 10 \mathrm{~V} / \mathrm{div}, V_{g s 1}(\mathrm{ch} 2): 20 \mathrm{~V} / \mathrm{div}, i_{s 4}(\mathrm{ch} 3): 20 \mathrm{~A} / \mathrm{div}\right)$

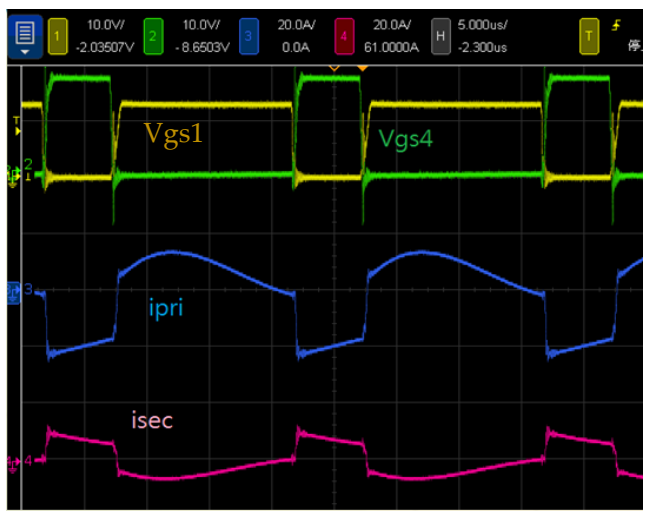

(d) $\left(V_{g^{s} 1}(\operatorname{ch} 1): 10 \mathrm{~V} / \mathrm{div}, V_{s^{s} 4}(\mathrm{ch} 2): 10 \mathrm{~V} / \mathrm{div}, I_{p}(\mathrm{ch} 3): 5 \mathrm{~A} / \mathrm{div}, I_{s e c}(\mathrm{ch} 4): 5 \mathrm{~A} / \mathrm{div}\right)$

Figure 10. Measured waveforms of the proposed converter operating under full load (500 W) in stage 2: (a) $V_{d s}$ and $V_{g s}$ waveforms of the switches S1 and S4, (b) current waveforms of switch S1, (c) current waveforms of switch S4, and (d) primary-side and the secondary-side current waveforms of the inductor $L$.

C. Stage 3: DC bus is stepped down to charge the battery

Figure $11 \mathrm{a}-\mathrm{c}$ illustrate the measurement results obtained when the converter operated under its full load of $500 \mathrm{~W}$ in stage 3. Figure 11 a shows $V_{d s}$ and $V_{g s}$ waveforms of the switches S3 and S4, respectively; the voltage stress was $200 \mathrm{~V}$ for both S3 and S4. The current waveforms of the switches S3 and S4 are displayed in Figure 11b. Figure 11c presents the primary-side and the secondary-side current waveforms of the inductor $L$.

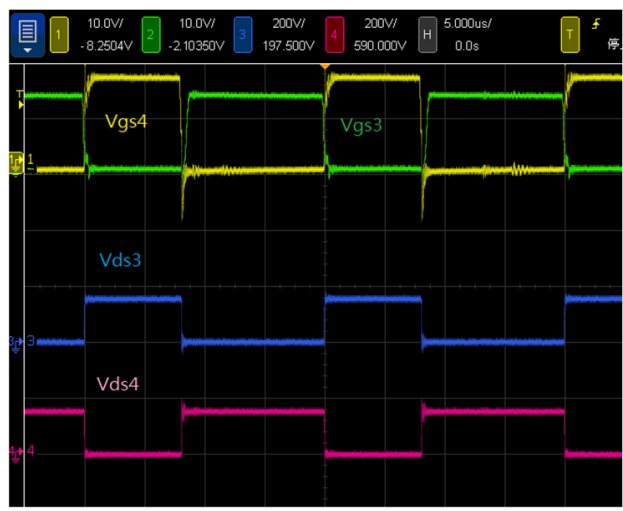

(a) $\left(V_{g^{54}}(\mathrm{ch} 1): 10 \mathrm{~V} / \mathrm{div}, V_{g^{s 3}}(\mathrm{ch} 2): 10 \mathrm{~V} / \mathrm{div}, V_{d s 3}\right.$ (ch3):200V/div, $\left.V_{d s 4}(\mathrm{ch} 4): 200 \mathrm{~V} / \mathrm{div}\right)$

Figure 11. Cont. 


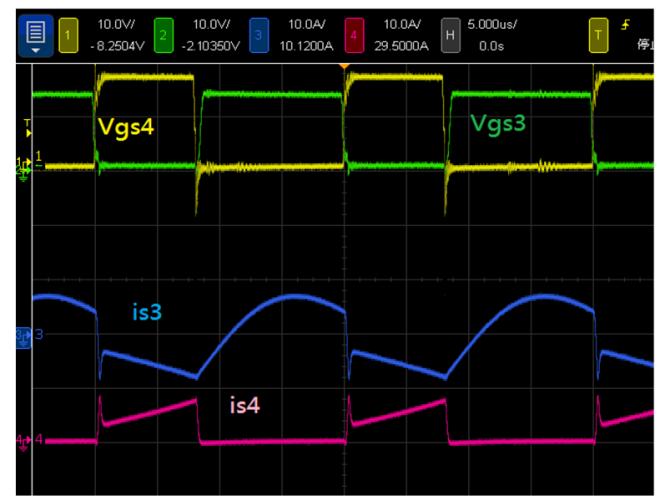

(b) $\left(V_{g^{4} 4}(\mathrm{ch} 1): 10 \mathrm{~V} / \mathrm{div}, V_{g^{s 3}}(\mathrm{ch} 2): 10 \mathrm{~V} / \mathrm{div}, I_{s 3}(\mathrm{ch} 3): 10 \mathrm{~A} / \mathrm{div}, I_{s 4}(\mathrm{ch} 3): 10 \mathrm{~A} / \mathrm{div}\right)$

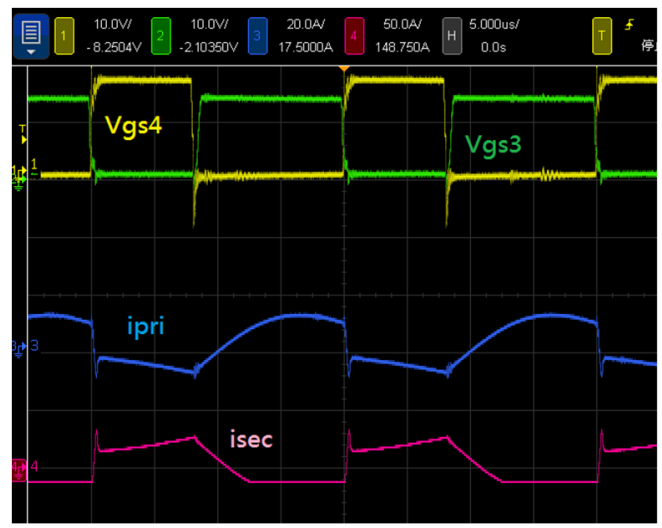

(c) $\left(V_{g s}(\mathrm{ch} 1): 10 \mathrm{~V} / \mathrm{div}, V_{8 s 3}(\mathrm{ch} 2): 10 \mathrm{~V} / \mathrm{div}, I_{p}(\mathrm{ch} 3): 20 \mathrm{~A} / \mathrm{div}, I_{s e c}(\mathrm{ch} 4): 50 \mathrm{~A} / \mathrm{div}\right)$

Figure 11. Measured waveforms of the proposed converter operating under full load (500 W) in stage 3: (a) $V_{d s}$ and $V_{g s}$ waveforms of the switches S3 and S4, (b) current waveforms of the switchs S3 and S4, (c) primary-side and the secondary-side current waveforms of the inductor $L$.

\section{Experimental Efficiency}

Figure 12 shows the efficiency curve of the proposed circuit. In stage 1, the maximum efficiency was $94.3 \%$ at an output power of $200 \mathrm{~W}$; when the load was $500 \mathrm{~W}$, the efficiency was $90.8 \%$. In stage 2 , the maximum efficiency was $94.1 \%$ at an output power of $250 \mathrm{~W}$; when the load was $500 \mathrm{~W}$, the efficiency was $90.1 \%$. In stage 3, the maximum efficiency was $95.2 \%$ at an output power of $200 \mathrm{~W}$; when the load was $500 \mathrm{~W}$, the efficiency was $91.3 \%$.

Figure 13 presents a comparison of the efficiency of the proposed bidirectional converter with that of the models presented in $[15,16]$ in step-up mode. The efficiency of the proposed converter was notably higher than that of the converter presented in [15] but lower than that of the converter presented in [16]. The proposed converter has three operating modes and high output power; however, the converter presented in [16] has only two operating modes.

Figure 14 presents a comparison of the efficiency of the proposed bidirectional converter with that of the converters presented in $[15,16]$ in step-down mode. The efficiency of the proposed converter was higher than that of the converter presented in [15] and lower than that of the converter presented in [16]; however, the converter presented in [16] has only two operating modes.

Figure 15 illustrates a comparison of the efficiency of the proposed three-port bidirectional converter with that of the converters presented in $[17,19]$ in step-down mode. The proposed converter demonstrated higher efficiency than that presented in [19] under light and medium loads, but it exhibited lower efficiency than that presented in [17]. However, the proposed converter requires fewer components and produces a greater power output. 


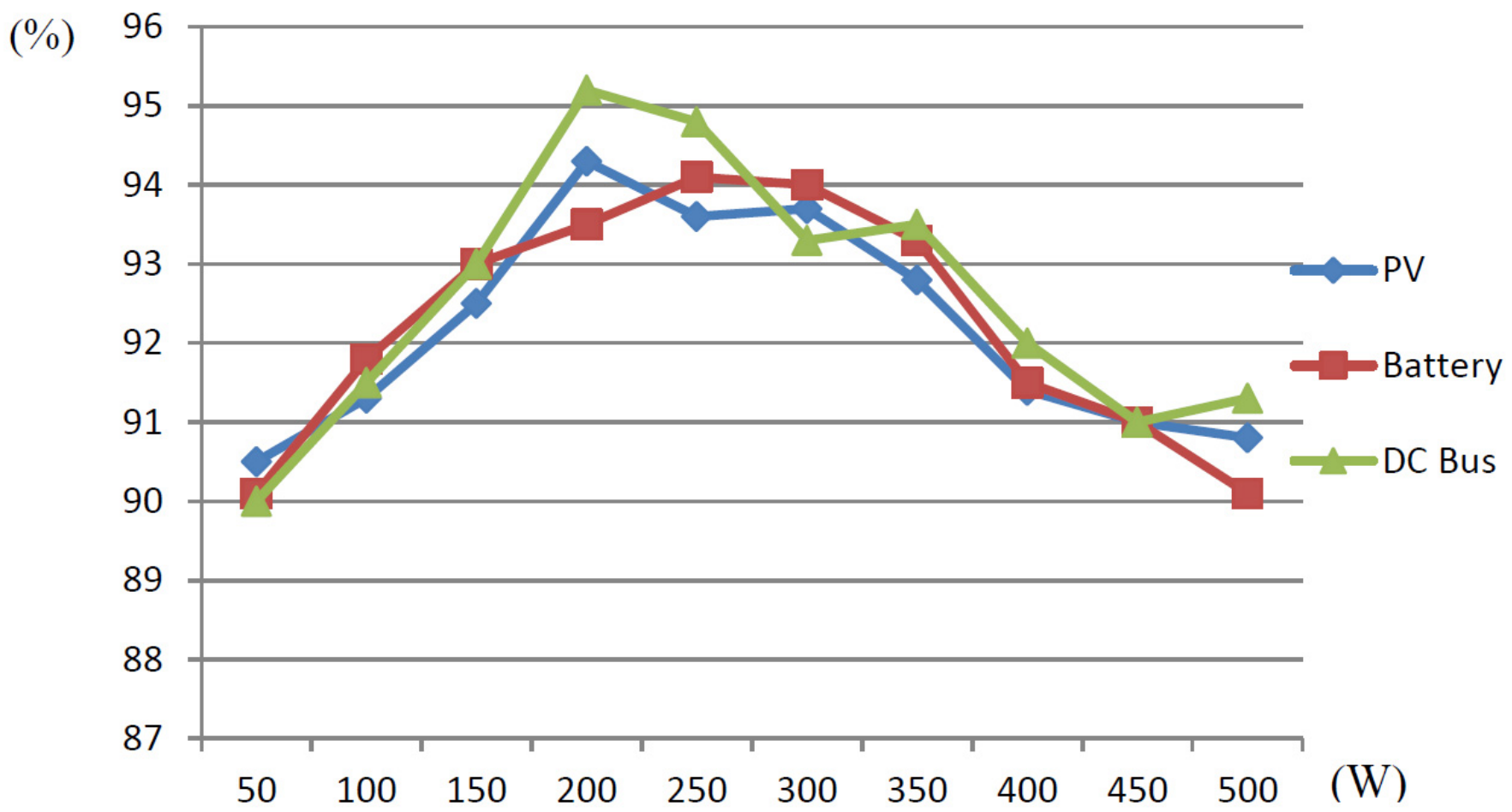

Figure 12. Efficiency curve of the proposed circuit operating at various stages.

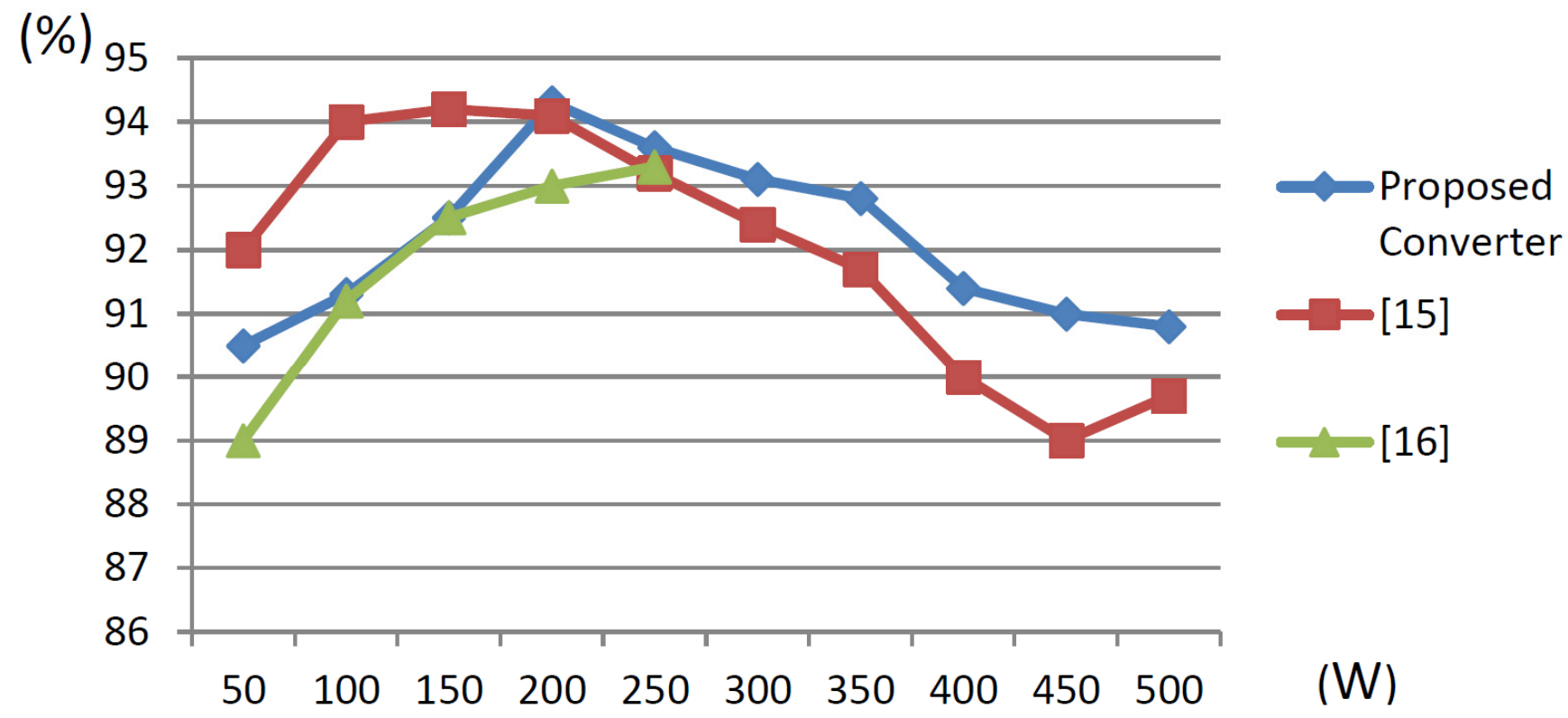

Figure 13. Step-up mode efficiency comparison between the proposed converter and those detailed in $[15,16]$. 


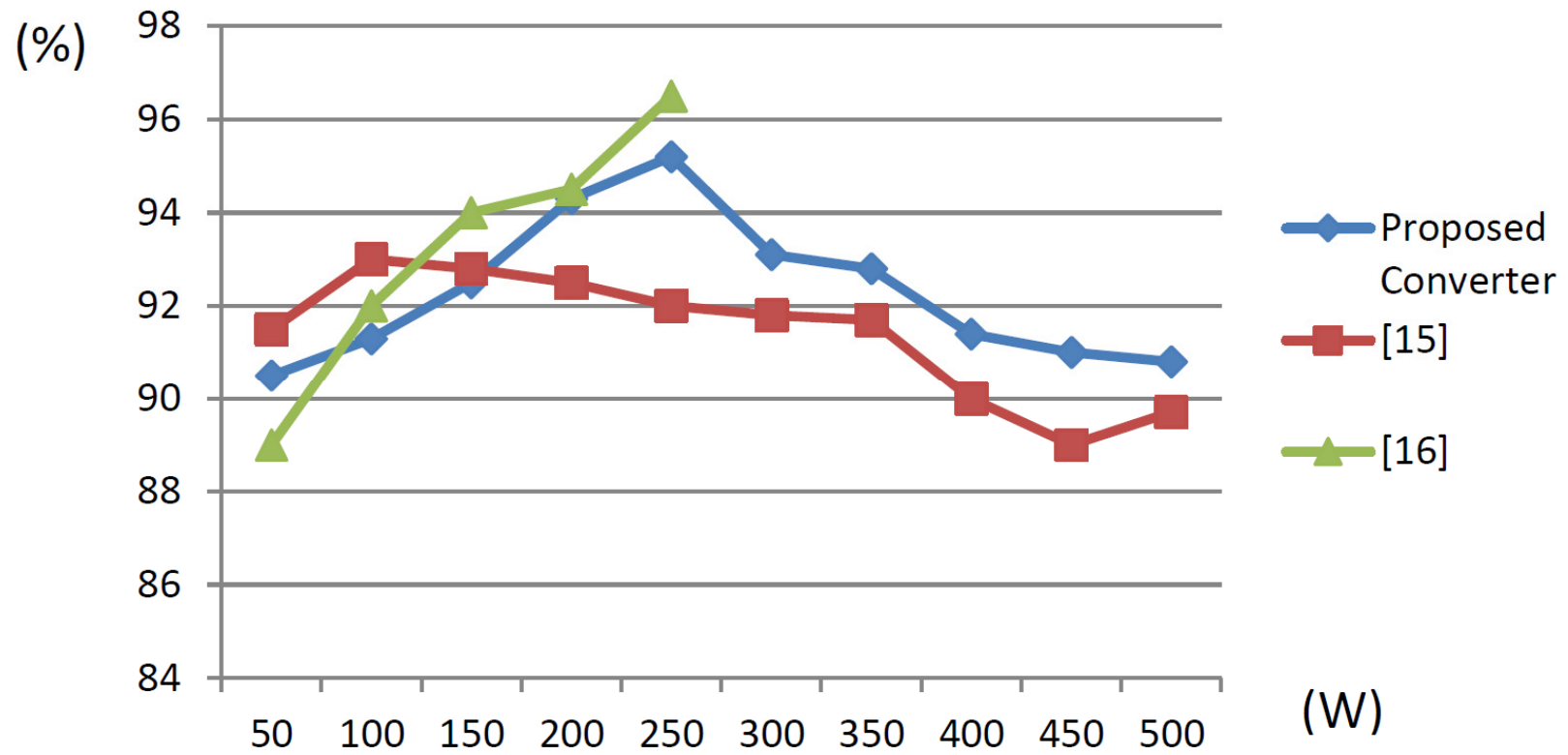

Figure 14. Step-down mode efficiency comparison of the proposed converter with those described in $[15,16]$.

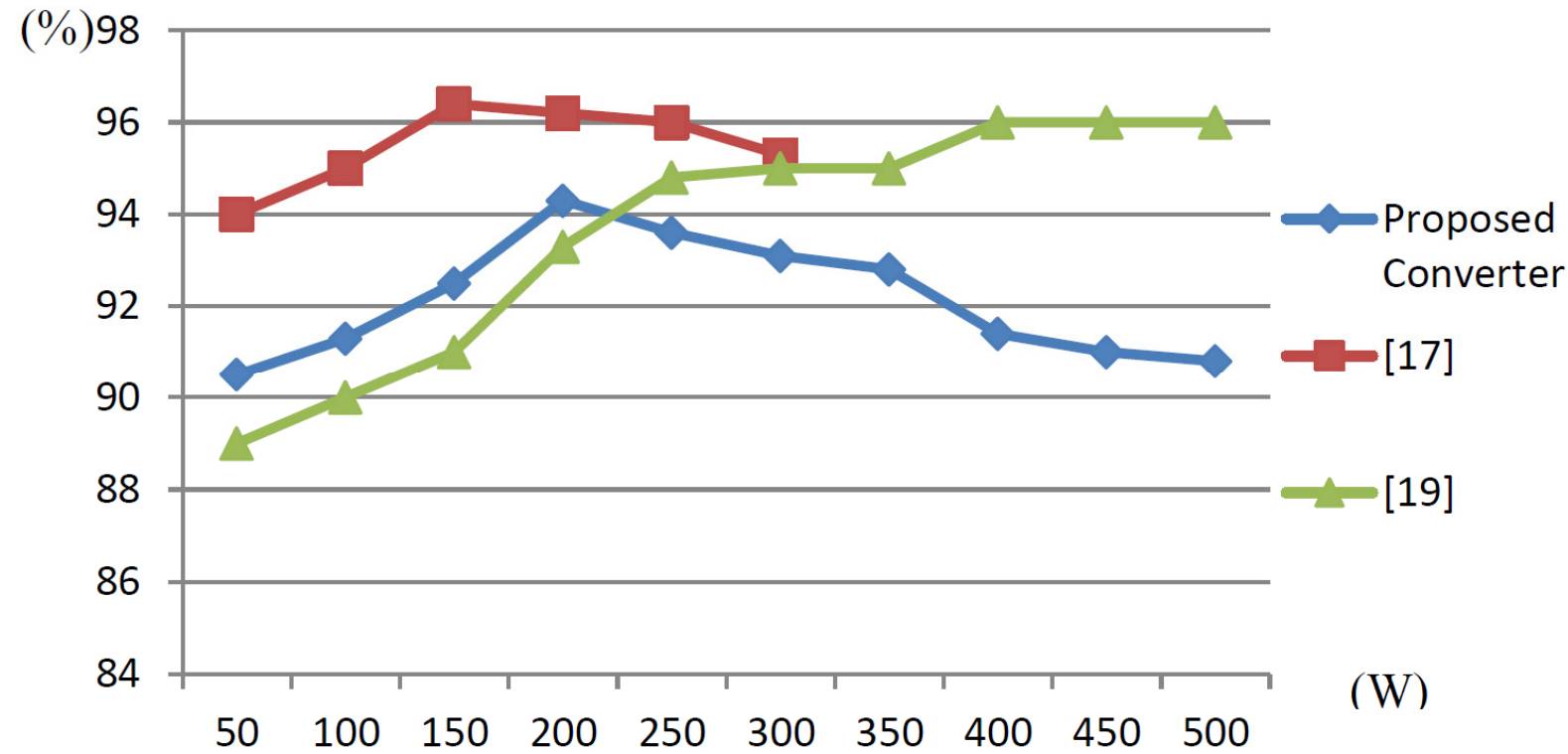

Figure 15. Step-up mode efficiency comparison between the proposed converter and those detailed in [17,19].

\section{Conclusions}

This paper presents a novel high-efficiency three-port bidirectional DC/DC converter for PV systems. A common-core coupled inductor was designed and adopted in the proposed converter. Power switches and diodes in the circuit were shared to achieve bidirectional operation. In step-up mode, the clamp capacitor was used to reduce the voltage spike on the main switches; in addition, the voltage-doubling capacitor recovered energy from the secondary-side leakage inductance. Furthermore, the input capacitors recovered the primary-side leakage inductance energy in step-down mode; thus, the converter improved the conversion efficiency. Finally, this paper details the implementation of a $500 \mathrm{~W}$ three-port bidirectional converter to verify the feasibility and the practicability of the proposed topology. According to the measurement results, the highest efficiency levels of the PV and the battery in step-up mode were $94.3 \%$ and $94.1 \%$, respectively; the highest efficiency in step-down mode was $95.2 \%$. 
Author Contributions: Conceptualization, Y.-E.W.; methodology, Y.-E.W. and S.-L.H.; formal analysis, Y.-E.W. and S.-L.H.; investigation, S.-L.H.; resources, Y.-E.W.; writing-original draft preparation, Y.-E.W.; writing-review and editing, Y.-E.W.; project administration, Y.-E.W.; funding acquisition, Y.-E.W. All authors have read and agreed to the published version of the manuscript.

Funding: This research received no external funding.

Institutional Review Board Statement: Not applicable.

Informed Consent Statement: Not applicable.

Conflicts of Interest: The authors declare no conflict of interest.

\section{References}

1. Ministry of Economic Affairs, Energy Bureau, Global Information. Network. Available online: https://www.moeaboe.gov.tw/ ECW/populace/home/Home.aspx (accessed on 20 May 2021).

2. Schmitz, L.; Coelho, R.F.; Martins, D.C. High step-up high efficiency dc-dc converter for module-integrated photovoltaic applications. In Proceedings of the 2015 IEEE 13th Brazilian Power Electronics Conference and 1st Southern Power Electronics Conference (COBEP/SPEC), Fortaleza, Brazil, 29 November-2 December 2015; pp. 1-6.

3. Seong, H.W.; Kim, H.S.; Park, K.B.; Moon, G.W.; Youn, M.J. High Step-Up DC-DC Converters Using Zero-Voltage Switching Boost Integration Technique and Light-Load Frequency Modulation Control. IEEE Trans. Power Electron. 2012, 27, 1383-1400. [CrossRef]

4. Ding, X.; Yu, D.; Song, Y.; Xue, B. Integrated switched coupled-inductor boost-flyback converter. In Proceedings of the 2017 IEEE Energy Conversion Congress and Exposition (ECCE), Cincinnati, OH, USA, 1-5 October 2017; pp. 211-216.

5. Yeh, C.H.; Hsieh, Y.P.; Chen, J.F. A novel high step-up DC-DC converter with zero DC bias current coupled-inductor for microgrid system. In Proceedings of the 2013 1st International Future Energy Electronics Conference (IFEEC), Tainan, Taiwan, 3-6 November 2013; pp. 388-394.

6. Muhammad, M.; Armstrong, M.; Elgendy, M.A. A Nonisolated Interleaved Boost Converter for High-Voltage Gain Applications. IEEE J. Emerg. Sel. Top. Power Electron. 2016, 4, 352-362. [CrossRef]

7. Liang, Z.; Guo, R.; Li, J.; Huang, A.Q. A High-Efficiency PV Module-Integrated DC/DC Converter for PV Energy Harvest in FREEDM Systems. IEEE Trans. Power Electron. 2011, 26, 897-909. [CrossRef]

8. Wen, P.; Hu, P.; Yang, H.; Zhang, L.; Deng, C.; Li, Y.; Xu, D. A two stage DC/dc converter with wide input range for EV. In Proceedings of the 2014 International Power Electronics Conference (IPEC-Hiroshima 2014-ECCE ASIA), Hiroshima, Japan, 18-21 May 2014; pp. 782-789.

9. Pressman, A.I.; Billings, K.; Morey, T. Switching Power Supply Design, 3rd ed.; Quanhua Books: New York, NY, USA, 2012.

10. Rashid, M.H. Power Electronics: Circuits, Devices and Applications, 3rd ed.; Prentice-Hall Inc.: Wilmington, DE, USA, 2003; 712p.

11. EPARC. Overview of Power Electronics, 2nd ed.; Quanhua Books: Taipei, Taiwan, 2013.

12. Jianhua, W.; Fanghua, Z.; Chunying, G.; Ran, C. Modeling and analysis of a buck/boost bidirectional converter with developed PWM switch model. In Proceedings of the 8th International Conference on Power Electronics-ECCE Asia, Jeju, Korea, 30 May-3 June 2011; pp. 705-711.

13. Duan, R.-Y.; Lee, J.-D. High-efficiency bidirectional DC-DC converter with coupled inductor. IET Power Electron. 2012, 5, 115-123. [CrossRef]

14. Wai, R.J.; Liaw, J.J. High-Efficiency-Isolated Single-Input Multiple-Output Bidirectional Converter. IEEE Trans. Power Electron. 2015, 30, 4914-4930. [CrossRef]

15. Gokul, K.K.; Emmanuel, B.P.; Ashok, S.; Kumaravel, S. Design and control of non-isolated bidirectional DC-DC converter for energy storage application. In Proceedings of the 2017 2nd IEEE International Conference on RTEICT, Bangalore, India, 19-20 May 2017; pp. 289-293.

16. Liang, T.J.; Lee, J.H. Novel High-Conversion-Ratio High-Efficiency Isolated Bidirectional DC-DC Converter. IEEE Trans. Ind. Electron. 2015, 62, 4492-4503. [CrossRef]

17. Chien, L.J.; Chen, C.C.; Chen, J.F.; Hsieh, Y.P. Novel Three-Port Converter With High-Voltage Gain. IEEE Trans. Power Electron. 2014, 29, 4693-4703. [CrossRef]

18. Zhang, B.; Wang, P.; Bei, T.; Li, X.; Che, Y.; Wang, Y. Novel topology and control of a non-isolated three port DC-DC converter for PV-battery power system. In Proceedings of the 2017 20th International Conference on Electrical Machines and Systems (ICEMS), Sydney, NSW, Australia, 11-14 August 2017; pp. 1-6.

19. Mira, M.C.; Zhang, Z.; Knott, A. Analysis, Design, Modeling, and Control of an Interleaved-Boost Full-Bridge Three-Port Converter for Hybrid Renewable Energy Systems. IEEE Trans. Power Electron. 2017, 32, 1138-1155. [CrossRef] 